\title{
ENTREVISTA COM O PROFESSOR ROBERTO LOBATO CORRÊA ${ }^{1}$
}

Roberto Lobato Corrêa é geógrafo e um dos principais estudiosos das questões urbanas no Brasil. Atualmente professor do Programa de Pós-Graduação em Geografia da Universidade Federal do Rio de Janeiro, escreveu inúmeros artigos e publicou diversos livros na área da geografia urbana e da geografia cultural. A Para Onde!? Teve a oportunidade de realizar a entrevista que segue no primeiro semestre de 2010 . Nela, o leitor poderá conhecer um pouco mais da trajetória profissional do professor, suas impressões sobre o Instituto Brasileiro do Geografia e Estatística, a importância da apreensão da realidade sob diferentes perspectivas epistemológicas, uma análise da geografia urbana na atualidade e do conceito de Rede. Por fim, o professor responde à nossa questão de praxe: Para Onde!?

Para maiores informações recomendados a visita da página pessoal: www.igeo.ufrj.br/robertolobatocorrea.

\section{PARA ONDE!?: Conte um pouco sobre sua trajetória profissional, destacando seu trabalho no IBGE, sua entrada na UFRJ e as diferenças de trabalho nessas duas instituições.}

ROBERTO LOBATO CORRÊA: Comecei minha vida profissional quando estava no segundo ano de graduação nesta universidade - Universidade do Brasil era o nome na época, atual UFRJ. Eu estava no segundo ano e em 1959 fui ser estagiário no IBGE, no que se chamava, na época, divisão de Geografia. Fiquei lá até 1993, cerca de 34 anos, então me aposentei. A minha trajetória na UFRJ é mais complicada, porque eu entrei aqui em 1971, como professor auxiliar e fiquei até 1978, quando tive que sair porque não podia acumular com o IBGE. A essa altura já não era mais estagiário no IBGE, já era geógrafo do IBGE, mas continuei de 1978 até 1987, exclusivamente na pós-

\footnotetext{
${ }^{1}$ Entrevista concedida ao geógrafo Rafael Zilio, mestrando em Geografia na UFRJ e ex-integrante do PET-Geografia UFRGS.
} 
graduação, pago com verba do CNPq, trabalhando no IBGE. Em 1987 fui cedido pelo IBGE e fiquei na Universidade até 1993, quando me aposentei no IBGE e fui contratado como professor do IBAM ${ }^{2}$ de 1993 a 1994. Em 1994 eu fiz concurso para professor assistente e fui aposentado em novembro de 2009 na compulsória com 70 anos de idade. $\mathrm{Na}$ verdade, minha trajetória já é longa, porque ela já tem cinquenta anos e meio de atividade profissional, bem diferenciada. A atividade profissional no IBGE caracterizase primeiramente por trabalhos de escala nacional, e esta é uma diferença em relação à Universidade. A Universidade tende a privilegiar estudos regionais, na área de influência da cidade que sedia aquela Universidade, enquanto o IBGE, que é um órgão público, da esfera federal, estuda o Brasil inteiro. Aliás, a Geografia do IBGE foi criada em 1939 para exatamente tornar o Brasil conhecido, porque ele não era conhecido. No IBGE o trabalho se faz em escala nacional e abrangendo temas que não têm a profundidade dos estudos da Universidade, não têm a verticalidade, mas horizontalmente são mais amplos. Há uma troca entre a Universidade, estudos parcialmente mais limitados e mais profundos, e o IBGE, estudos parcialmente mais amplos e menos profundos. É uma complementaridade muito boa, porque você tem duas escalas de análise, em termos espaciais, e duas escalas de aprofundamento. No caso IBGE a minha experiência da década de 1960 foi uma experiência em parte ligada a estudos que o IBGE ainda fazia para conhecer o Brasil, mas a partir de meados dos anos 1960 o IBGE passou a se envolver, primeiramente através do que hoje se chama IPEA $^{3}$ - Ministério do Planejamento, com atividade de planejamento na esfera federal, e a Universidade continuou seu trabalho de fazer estudos em escalas espaciais menores, bem mais profundos. É uma diferença muito sensível. De qualquer maneira, para mim foi muito útil porque quando vim para a Universidade, eu não tinha horário integral, mas comecei a participar de tarefas em pesquisas em áreas minúsculas, com nível de maior rigor acadêmico do que o próprio IBGE, mas levava isso para o IBGE e trazia do IBGE para a Universidade um conhecimento numa escala mais ampla. Então, para mim, foi extremamente enriquecedor ter essa dupla experiência.

\footnotetext{
${ }^{2}$ Instituto Brasileiro de Administração Municipal.

${ }^{3}$ Instituto de Pesquisas Econômicas Aplicadas.
} 


\section{PARA ONDE!?: Como o senhor vê o papel da Geografia no IBGE hoje?}

RLC: O IBGE, quando foi criado no final dos anos 30, tinha uma função, no governo do Estado Novo, de desbravar o Brasil. Uma das políticas de Getúlio Vargas foi a de integrar o Brasil, desbravar, criar meios para uma unidade nacional. O Brasil era totalmente desconhecido. Em 1939 ainda não havia uma geração de geógrafos, já que a primeira geração entrou na Universidade em 1934 em São Paulo e em 1936 no Rio, então não havia uma tradição. O IBGE passou a desenvolver essa pesquisa de desbravamento e de conhecimento do território nacional, e a Universidade era inexistente.

A partir de 1968, numa política paradoxal, porque uma política da Ditadura Militar, mas numa política que se fazia necessária a expansão dos cursos universitários no Brasil, fez-se uma reforma universitária que permitiu a criação de um número considerável de unidades. Aí começaram as pesquisas na Universidade. Esse departamento [de Geografia], a UFRJ criou o mestrado [em Geografia] em 1972, e aí começam uma série de estudos substituindo o IBGE, que passa a trabalhar mais e mais na escala nacional. Isso vai até 1979/1980, num processo de liberação política do país e, com a introdução do neoliberalismo, a ideia de planejamento nacional, planejamento com uma conotação espacial, desaparece, e a Geografia do IBGE vai progressivamente definhando, ao mesmo tempo em que as velhas gerações de geógrafos começam a se aposentar.

Em 1982 houve uma débâcle de aposentadorias porque com o tempo de serviço havia condições favoráveis para a aposentadoria. Em 1991, no governo Collor, houve um incentivo à aposentadoria com medo de perder uma série de vantagens adquiridas, e o IBGE definha mais ainda. Este processo é como se fosse uma ladeira que vai até não se sabe onde, geralmente vai até o fundo do poço, essa crise da Geografia do IBGE. Eu diria que o IBGE hoje está à procura do que fazer, com geração de geógrafos novos, sem muita experiência. Todos os antigos da geração de Orlando Valverde, de Nilo Bernardes já se aposentaram em 1982. A geração que é mais ou menos a minha geração se aposentou entre 1991/1992/1993. Então, hoje existem geógrafos muito jovens, inclusive geógrafos com menos de 30 anos de idade, formados há dois, três, quatro, cinco anos, e criou-se a ideia de que a Geografia deveria estar a reboque da Estatística, 
de produzir e armazenar os dados que a Estatística publicar, e não o contrário, ou seja, a Estatística produzia dados que interessavam para o conhecimento do Brasil numa perspectiva geográfica. Eu acho lamentável, mas eu entendo (e não quer dizer que eu aceito) que houve uma mudança política nacional nesse longo período, ou seja, a universidade ganha seu papel, se espalha pelo Brasil inteiro, começa a fazer pesquisas, começa a aparecer os cursos de pós-graduação, sobretudo pós-1980 e pós-1990 cada vez mais, e começa a fazer pesquisas que o IBGE fazia nos anos 1950 e 1960. O IBGE entra na escala espacial, mas vai perdendo um pouco, porque era uma análise que se fazia ligada ao sistema de planejamento. À medida em que isso é desativado, é como se a geografia do IBGE estivesse em crise. O melhor exemplo disso é que a Revista Brasileira de Geografia, criada em 1939, é fechada em 1995.

\section{PARA ONDE!?: Olhando sua obra podemos ver uma clara tendência marxista. No entanto, você também passou pela geografia teorética e mais recentemente têm tratado de estudos culturais. Como é para você transitar por essas diferentes perspectivas da Geografia?}

RLC: Eu diria que é enriquecedor, e acho que todos os geógrafos deveriam conhecer duas ou três perspectivas da Geografia. Hoje deveria haver, de uma maneira dialética, uma complementaridade entre essas diferentes perspectivas. Eu aprendi muito com a geografia teorética/quantitativa no mestrado que eu fiz em Chicago, sob a orientação do professor Brian Berry. Na minha dissertação de mestrado há 48 equações de regressão, e aprendi muito. Acho que a geografia teorética/quantitativa tem alguns equívocos, sobretudo no nível epistemológico, de apreensão da realidade e da teoria do conhecimento. Ela é fundada no neopositivismo e, mesmo que seja um neopositivismo brando, ela não tem essa perspectiva crítica porque ela se apóia muito em modelos que são hipotético-dedutivos ou com uma pretensa objetividade, e é acrítica. Ela está muito mais ligada ao status quo do que a qualquer movimento de resistência, de mudança. A geografia cultural, por outro lado, me enriqueceu muito pelo fato de que ela deixa de lado essa perspectiva essencialista do marxismo, e passa a adotar uma perspectiva 
existencialista. Numa sociedade plural, numa sociedade de classes, com uma fragmentação enorme, o mundo não é visto nem vivido da mesma maneira, e os diferentes grupos socias e plurais, étnicos e religiosos, e o que mais for, constróem, a partir de sua vivência, um mundo de significados próprios, que podem ser alienantes, mas que são reais, reais no sentido de que eles são voltados para as experiências vividas deles, da existência deles, e reconstróem o mundo à sua maneira. Uma das tarefas da geografia cultural é tornar inteligível o que os outros pensam do espaço, não quer dizer que seja concordar ou discordar, mas o que é o espaço de um grupo "x", de um grupo "y", e como isso tem retorno sobre as práticas socias e espacias desses grupos. Para mim, a geografia cultural teve um sentido de quebrar o essencialismo do marxismo. Eu acho que o marxismo é um campo riquíssimo, com possibilidades enormes de compreender o mundo através das relações sociais e desse movimento das lutas sociais, mas ele se recusa - eu diria não o marxismo, mas os marxistas, os neomarxistas, muito dos quais de má formação no próprio marxismo. Acredito que me beneficiei muito, na minha avaliação, dessa vivência nessas três perspectivas. E mais: a minha primeira vivência foi na geografia francesa, vidaliana. Seria muito bom se todos passassem por isso, mas evidentemente demora muito tempo, como também demanda muito estudo, muita leitura, muita crítica, muita autocrítica, muitos debates, muitos atritos consigo e com os outros. Mas é o processo, pois a ciência não é um mar de rosas que você caminha: tem contradições, conflitos e angústias. É essa pluralidade que me permite analisar o modelo quantitativo, ver o que ele tem de positivo e de negativo, que me permite entender o mundo e a história social através do marxismo, que me permite entender as lógicas de determinados grupos que a partir de suas experiências veêm o mundo, vivênciam o mundo e pensam o mundo de uma maneira própria. Eu acho que essas três perspectivas se complementam, o que não quer dizer que eu abandonei algumas teses do marxismo, pois acho que o marxismo permite, através da própria natureza dialética, estas possibilidades todas. 


\section{PARA ONDE!?: O que o senhor destacaria dos estudos de geografia urbana na atualidade (novas tendências, resgates de teorias ou conceitos e metodologias)?}

RLC: Um dos problemas que eu vejo na geografia brasileira, não exclusivamente em geografia urbana, é que são muito poucos aqueles que estudam, que sistematicamente estão lendo. Portanto, que nós estamos resgatando, às vezes, são coisas que foram esquecidas simplesmente por falta de interesse, e muitas coisas que nos estamos tomando como um novo, não é tão novo assim na ciência. $\mathrm{N}$ tradição brasileira todas as introduções de coisas novas, aqui no Brasil, se fazem com 10, 15, no máximo 20 anos de atraso em relação aos Estados unidos e à Europa. Não tenho a menor dúvida de que no contexto da produção do conhecimento, do controle sobre esse conhecimento, nós estamos à reboque, queremos criar uma geografia brasileira. O que que é uma geografia brasileira? Do ponto de vista epistemológico não existe. Do ponto de vista teórico, ao nível da apreensão da realidade brasileira priorizada, isso é possível, mas com que base epistemológica? A epistemologia brasileira não existe. A epistemologia não tem pátria. A geografia urbana tem sido muito limitada. Por exemplo, os estudos sobre redes urbanas, que são fundamentais para se entender o espaço brasileiro, estão desaparecendo ou simplesmente estão sendo relegadas a um plano muito secundário. E parece que o estudo de redes urbanas só que tem valor na esfera do planejamento, quando na verdade se trata de um conhecimento das redes urbanas brasileira, ou paulista ou nordestina, que são importantes para a compreensão do espaço brasileiro. No que diz respeito a um espaço intraurbano há limitações muito sérias. A literatura dos anos 1920, 1930, 1940, 1950 e 1960, que é variada, que não é homogênea, não é conhecida. Hoje nós estamos sob a influência de um marxismo, de um neomarxismo, posto à tona por Henri Lefebvre. Acho que ele tem contribuições enormes, mas eu diria que são muito francesas, muito parisienses, e algumas coisas que ele afirma já foram ditas por outros, não da maneira como ele disse, mas o fato de dizer já possibilita desenvolver novas interpretações.

Há limitação na geografia urbana brasileira. Houve a limitação temática, houve a limitação teórico-epistemológica, e houve a limitação temática. Hoje não se discutem temas que são importantes, e que no Brasil têm um sentido muito grande: ênfase no 
espaço intraurbano no sentido da produção de espaço é muito importante, mas não é tudo. Acho que uma das características da geografia urbana brasileira, ou melhor, de toda a geografia brasileira, é a dificuldade ou a inexistência de abranger os múltiplos temas que o real permite focalizar. É como se nós batêssemos a cada vez numa mesma tecla temática, que tem problemas depois de certo tempo, porque se esgotam as possibilidades de um novo conhecimento. Mas o que eu acho mais dramático na nossa geografia urbana é a dificuldade de se transitar com diferentes autores em diferentes linhas e saber utilizá-las como uma mistura, uma combinação ou uma complementaridade que pode contribuir para a compreensão de um espaço urbano da cidade ou da rede urbana de uma maneira muito sólida. De qualquer maneira, a geografia urbana parece ser o grupo mais mais ativo, mais importante na geografia brasileira, na atualidade, e isso é muito bom.

\section{PARA ONDE!?: O conceito de Rede é um dos mais estudados na Geografia} atualmente, e o senhor tem uma importante contribuição nesse sentido. No entanto, como qualquer questão estudada em demasia, é preciso ter cuidado para não cair numa banalização do conceito. $O$ que o senhor destacaria de importante nesse sentido e sobre a articulação desse com outros conceitos geográficos?

RLC: A rede geográfica é uma rede social por definição, mas nem toda rede social é uma rede geográfica. A rede tem uma nítida espacialidade de localização dos nós, dos centros urbanos, dos focos, das junções e das articulações que se coligam no espaço, integrando áreas que têm sentidos diferentes, seja na produção, seja na densidade demográfica, seja na inserção em diferentes esferas do mercado. A rede tem esse sentido integrativo: ela é que permite, objetivamente, fazer com que você tenha uma unidade nacional. Se não há uma rede, como se irá fazer? Seja do que for: seja uma rede do Ministério da Guerra ou do Ministério da Economia, seja na rede da igreja católica, seja na rede dos movimentos sociais, seja uma rede de uma grande corporação. A idéia de rede permite que o espaço seja integrado através das conexões focalizadas em nós e núcleos que se articula entre si. Isso significa dizer que existem vários tipos de redes sociais. Mais do que sociais, geográficas, pois elas só são compreensíveis ao serem espacializadas. Ora, ao serem espacializadas, elas permitem estabelecer contatos e 
conexões com outros conceitos da geografia, como território, região, conceitos utilizado pela geografia como área de alta densidade, área de baixa densidade, zonas pioneiras, zonas de complexidade industrial, que não são conceitos, são apenas noções que nós geógrafos utilizamos. As redes geográficas estão inseridas em, por exemplo, zonas pioneiras, zonas de ocupação antiga, áreas de pecuária extensiva, em áreas de complexidade industrial, em áreas urbanizadas, em áreas de baixa densidade demográfica, em áreas ainda habitadas por índios, e elas funcionam ao mesmo tempo como uma marca das condições estruturais em que elas estão assentadas e como matrizes, no sentido de que elas devem, em princípio, influenciar a continuidade ou uma mudança controlada da estrutura sócio-espacial. Permite estabelecer novos contatos por medições com outros conceitos da geografia, e é isso que dá força ao conceito de rede, que é um conceito que se tornou muito importante porque a própria realidade estava demandando isso a partir da formação de redes das grandes empresas multinacionais. É isso que trouxe à tona a importância do conceito de rede. Se você imaginar, o mundo hoje está estruturado em parte através das grandes redes, redes mundiais. O conceito de globalização está ligado ao conceito de rede: não existe globalização sem rede.

\section{PARA ONDE!?: Professor, para onde?}

RLC: Essa é uma questão importante. Para onde no momento em que você tem uma expansão brutal e necessária dos cursos de graduação e também de pós-graduação. Me parece que, atualmente, são 49 cursos de pós-graduação no Brasil em maio de 2010 e está sendo criado mais um. Esse "Para Onde" passa por aí, pela criação de cursos de graduação e pós-graduação. E aí a questão é levada para a qualidade do que se ensina, e para as condições em que se processa o ensino da geografia. No caso do Brasil, toda difusão muito rápida tende a gerar uma diminuição da qualidade média, e é o que está acontecendo na pós-graduação. É uma questão para que a AGB, por exemplo, discuta o problema da formação do geógrafo. Talvez seja o problema mais premente da AGB. A ANPEGE discutiu o problema da formação do mestre e do doutor. Nessa discussão podem nascer caminhos distintos para o desenvolvimento da geografia. Um ponto, para mim, é certo: o desenvolvimento da geografia brasileira pressupõe um pluralismo. Qualquer modelo monotônico, de uma única linha metodológica e de uma única matriz 
teórica acaba, com o tempo, se deteriorando. Eu vejo que a crise da geografia francesa nem todos concordarão com isso - se deve, em grande parte, a isso. Presa que ficou ao modelo vidaliano.

"Para Onde"? Então, uma pergunta: será que isso depende apenas do geógrafo ou depende de como os geógrafos sabem negociar com a sociedade, com o Estado, para encaminhar a Geografia? Para formar o quê? Eu vejo uma distinção essencial: a formação do cidadão comum, que é o médico, o maquinista de trem, o motoboy, o bancário, o agricultor, enfim, o homem comum, que precisa ter uma noção de geografia no sentido de que ele está situado no espaço, ele é parte da organização espacial e ele interfere, de uma certa maneira, nessa organização espacial. Aí entra o papel do professor de Ensino Médio para passar essa Geografia para o cidadão comum. E a outra é a formação de quadros, com pesquisa que produz um conhecimento novo, que é ao nível da pós-graduação. Mas "ara onde" é uma pergunta interessante. Qual é o papel da Geografia? É formar o quê? Formar um cidadão? Que tipo de cidadão? Que tipo de cidadão se quer, e quem quer esse tipo de cidadão? Acho que é uma questão que nós nos privamos de debater ou, se o fazemos, fazemos num nível quase que político-partidário ou então com uso de jargões e clichês, e nós não iremos a lugar algum usando jargões e clichês, porque isso acaba se esvaziando. É uma questão para se pensar. Será que nós temos condições de preparar o caminho para onde nós vamos? Acredito que, no momento, não temos. Acredito que a $\mathrm{AGB}$ perdeu muito do seu sentido e que a ANPEGE está se encaminhando muito mal. Sobretudo porque ambas, principalmente a ANPEGE, são pressionadas por esta loucura que é a política de incentivos, de obrigatoriedade, do CNPq e da CAPES - a produção quantitativa, em grande quantidade e sem qualidade alguma. Essa questão do "para onde", na verdade, deveria ser debatida. Eu não vou dar uma "receita de bolo" de para onde se deve ir, porque o para onde a geografia será construído na prática mesmo, com os geógrafos debatendo, discutindo e fazendo proposições. De qualquer maneira, devemos pensar a organização espacial com base no desenvolvimento das possibilidades humanas, e em que medida a Geografia tomaria para isso. Eu acho que a geografia deve caminhar - mas isso não é fácil, é muito difícil, há vários conflitos e contradições no meio - no sentido de criar uma sociedade mais justa. Por isso vou parar por aqui, senão vou começar a utilizar jargões, clichês e frases preparadas, e isso não satisfaz. 